\title{
Ecomunitarismo, Reforma y Revolución en América Latina: Uruguay hoy
}

\author{
Prof. Dr. Sirio Lopez Velasco*
}

\begin{abstract}
Resumen
En este trabajo, nos proponemos explicitar los conceptos de ecomunitarismo, poder y revolución, y analizar a partir de ellos la actuación de la izquierda uruguaya en su aproximación al gobierno y en el ejercicio del mismo desde 2005.
\end{abstract}

Palabras clave: ecomunitarismo, política uruguaya, política latinoamericana

\begin{abstract}
In this paper we explain the concepts of ecommunitarism, power and revolution, and we analyzes the performance of the Uruguayan left on her approach to the government and her behavior on government since 2005.
\end{abstract}

Key words: ecommunitarism, Uruguayan politics, Latin American politics

* Universidade Federal do Rio Grande, Brasil - dlamji@hotmail.com 
Ecomunitarismo, reforma y revolución en América Latina: Uruguay hoy - Dr. Sirio Lopez Velasco

\section{Introducción}

He definido el ecomunitarismo como el orden socioambiental utópico poscapitalista capaz de pautarse por las tres normas de la ética (que hemos deducido argumentativamente de la pregunta que la instaura y que nos obligan, respectivamente, a luchar por hacer realidad nuestra libertad individual de decisión, a realizarla consensualmente, y a preservar-regenerar una naturaleza humana y no humana sana). Ese orden, a pesar de utópico, es un horizonte indispensable para orientar la acción diaria, y tomándolo como referencia, sopesar la significación de cada reforma y revolución. Nos proponemos evaluar la actual experiencia de Uruguay desde esa perspectiva utópica, y a la luz de las siguientes nociones de 'poder', 'revolución' y 'reforma'. He definido el "poder" como la relación social que media entre los que deciden y los que no lo hacen, y he mostrado, por un lado, que el capitalismo niega las tres normas fundamentales de la ética, lo que incluye la negación de la capacidad de decidir de cada individuo en el día a día, en especial de los asalariados y de los excluidos del trabajo (violando la primera norma de la ética), y, por otro, que la "revolución" consiste en ampliar dicha capacidad, bien por la ampliación del número de los que ya deciden (como sucede cuando la familia machista y patriarcal amplía el poder de decisión al conjunto de sus miembros, superando el monopolio ejercido por el pater familias), o por la sustitución de los que la ejercen (como sucedió en gran medida en Francia con la ascensión de la burguesía que desplazó a la aristocracia feudal en 1789, en la Rusia de 1917 y en la revolución cubana). Nuestro desafío es no infravalorar la primera alternativa, sin olvidarnos ni renunciar a la segunda. Por otro lado, la experiencia muestra que, después de cualquier "revolución", se impone la necesidad diaria de "reformas", si no queremos que la revolución se petrifique. A propósito, esa es otra cara de la vieja discusión sobre la dialéctica revolución-reforma (que por lo menos desde Lenin dejó claro que ninguna reforma puede juzgarse individualmente, sino sobre el fondo del contexto que la caracteriza como revolu- 
cionaria o no). Creo que al filósofo del siglo XXI en A. Latina no le cabe ni el papel del ideólogo alemán criticado por Marx en 1845 ni el papel del "intelectual orgánico" del marxismo-leninismo que subordina el filósofo al papel dirigente del Partido supuestamente de vanguardia; una digresión: en momentos en que la clase obrera ha disminuido cuantitativamente y se ha modificado cualitativamente, con centrales sindicales que de hecho aceptan los límites del capitalismo, ya suena a museo la invocación de cualquier "partido obrero de vanguardia"; la tarea crítico-utópica ecomunitarista hoy es colocada en manos de un bloque social heterogéneo, con forma de movimiento, que agrupa a los asalariados, los excluidos de la economía capitalista formal, las llamadas "minorías" (que a veces son mayorías, como las mujeres, y algunas comunidades étnicas en algunos países), las minorías activas (sobre todo en movimientos, partidos, sindicatos y redes y organizaciones no gubernamentales, en especial muchas de carácter ambientalista), los pueblos indígenas que sin asumir una postura identitaria a-histórica esencialista, quieren permanecer y transformarse sin aceptar el dogma de los "valores" capitalistas de la ganancia y del individualismo, y los movimientos de liberación nacional que combaten el recrudecido imperialismo yanqui-europeo. Como dije, desde mi condición de filósofo analizaré la situación de Uruguay en la perspectiva ecomunitarista de la reforma y.la revolución, aclarando que del ecomunitarismo, que pretende propiciar el libre y multifacético desarrollo de los individuos asociados solidariamente por decisión libre, hacen parte, resumidamente: a) una economía solidaria y ecológica basada en el principio que estipula "de cada uno según su capacidad y a cada uno según sus necesidades" y respetuosa de la norma ética que exige preservar-regenerar una naturaleza humana y no humana sana pautada por los grandes equilibrios ecológicos, b) una pedagogía problematizadora (según la entendió Paulo Freire y que ampliamos en enfoque socioambiental), de la que hace parte una educación sexual que fomenta el libre placer compartido y condena el machismo, el sexismo, la culpabilización de 
la masturbación y de la homosexualidad, y, c) una "política de todos" que fomenta la práctica de la democracia directa y, para las representaciones que se revelen indispensables, instrumenta la rotatividad de los representantes electos y revocables por sus electores en cualquier momento; esa política se propone la reconciliación solidaria de individuos y comunidades a nivel planetario, realizando la efectiva constitución del "género humano" como familia que (aunque atravesada por conflictos) resuelve los diferendos en provecho de todos y cada uno porque se ha pasado (como quería Marx) del gobierno de los hombres a la compartida administración de las cosas.

\section{La aproximación de la izquierda uruguaya al gobierno}

La realidad latinoamericana ha sido rica en derrotas, intentos frustrados y decepciones en nuestra búsqueda de superación del capitalismo. Si Cuba resiste heroicamente 47 años después de su Revolución, los problemas que la aquejan en el día a día (desde el tipo-cantidad de alimentos accesibles a la población que no posee los pesos fuertes equivalentes al dólar, hasta la renacida prostitución habanera para satisfacer a gringos y la ausencia de espacios verdaderamente abiertos al debate libre de las ideas) han llevado a que muchos de sus antiguos admiradores-defensores (incluyendo a miembros de la clase filosófica) se hayan hecho cada vez más renuentes a renovarle su estima, cuando no han cambiado su tesitura hacia una posición abiertamente crítica (aunque sin llegar en su mayoría al caso paradigmático de transformación anticubana de Vargas Llosa). Estamos a la espera de voces cubanas que nos digan qué le falta a su revolución para ser mejor; no en el sentido capitalista sino en el de la utopía marxiana del comunismo, resumida en los principios de la "libre asociación de los productores libres" y "de cada uno según su capacidad y a cada uno según su necesidad", a fin de propiciar el multilateral desarrollo del individuo universal. Al mismo tiempo hemos sufrido las derrotas de Allende en Chile, de la revolución sandinista y de las esperanzas 
abiertas por el velazquismo en Perú. Sobre el caso de Allende es llamativo que varios intelectuales chilenos alegan hoy que el Presidente debería haber procedido mucho más precavidamente, no amparando las nacionalizaciones de industrias medianas, no irritando a los EEUU (con la nacionalización del cobre) y no polemizando con la Democracia Cristiana de Frei (que acabó gestando el golpe que instalaría en el poder a Pinochet). Ahora bien, nos preguntamos: ¿para qué llegó al gobierno entonces Allende? Porque de hecho lo que nos dicen esos intelectuales es que Allende tendría que haber hecho un gobierno "a la Frei"; pero en ese caso, ¿donde quedaría la perspectiva socialista de la Unidad Popular, articulada en dos enormes Partidos que se definían por el socialismo (el partido Socialista y el partido Comunista?). No resisto a comentar de paso que esa curiosa posición cobra hoy en el gobierno de Lula (y espero que sepamos derrotarla en el Frente Amplio de Uruguay) la figura de una curiosa esquizofrenia que desde el gobierno pide a los militantes que lo llevaron al triunfo electoral que entiendan que las "responsabilidades de la gobernabilidad" imponen la prosecución de políticas macroeconómiacas neoliberales (centradas en el pago de la deuda externa y el control de la inflación); ante tal declaración que catalogamos como esquizofrénica porque incluso lleva a que una misma persona diga "esto lo pienso como militante" (por ejemplo: hay que restringir drásticamente el pago de la deuda externa si queremos tener recursos para las urgentes e imprescindibles políticas sociales), pero "lo otro lo digo como miembro del gobierno" (por ejemplo: hay que pagar religiosamente la deuda externa para respetar los compromisos internacionales asumidos, léase con el FMI), nos preguntamos: entonces ¿para qué se invocó al socialismo y se dijo durante más de 20 años que la política neoliberal era nefasta?; porque, además, para aplicarla, mejor dejar el poder en manos de los neoliberales, que se la saben de memoria. Por eso me gustaría oír las voces de aquellos que creen que siendo legítima la aspiración socialista de Allende nos digan qué creen que salió mal en la tragedia que terminó por instalar la larga dic- 
tadura de Pinochet, y, al cabo de ésta a dos Presidentes (Lago y Bachelet), supuestamente socialistas, que en nada parecen retomar el camino allendista (a no ser que estemos equivocados por falta de información). Si en el caso velazquista se puede decir que la fragilidad de aquel proceso estribó en la dependencia hacia una sola persona cuya permanencia en situación de mando era transitoria pues se subordinaba al obligado relevo de la jerarquía militar (cuya gran parte obedecía a su amo estadounidense), aún estamos esperando una sincera autocrítica de la dirigencia y la militancia sandinista sobre lo ocurrido con su revolución, antes de la reciente vuelta de Daniel Ortega al gobierno. Por nuestra parte, aquellos filósofos que pertenecemos a países donde aún ninguna alternativa de gobierno carga con reales expectativas de cambios en la óptica del pensamiento de liberación, o que recién empiezan a actuar (como es el caso de Uruguay), tenemos la obligación de reflexionar (sabiendo del poder inmenso de la gran prensa en la formación de opiniones alienadas, ya criticadas por Habermas en su evaluación de la emergencia y el ocaso de la "opinión pública), sobre nuestra incapacidad para convencer a la gente y encontrar mecanismos de acceso a las instancias de decisión con y por fuera de los mecanismos clásicos de la democracia representativa burguesa.

Ahora bien, ¿con qué Programa llega la izquierda uruguaya (nucleada en el Frente Amplio, que sumó a sectores del Centro en el Encuentro Progresita) en noviembre de 2004?

El Uruguay se divide en 19 Departamentos, siendo Montevideo uno de ellos, donde se concentra la mitad de los 3,5 millones de uruguayos. En Uruguay la izquierda se unió casi toda, y también con sectores provenientes de los partidos de derecha y de centro, en torno al Frente Amplio (FA) desde 1971, año en que obtuvo el 18\% de los votos a nivel nacional, entre los que se contaron los de la guerrilla urbana del MLN, indirectamente representada en la coalición. Desde hace tres lustros el FA gobierna Montevideo, sufriendo, hasta 2005 cuando el FA llega al gobierno 
nacional, el boicot financiero del gobierno central que no dejaba de ayudar a los otros 18 Departamentos del país, gobernados hasta entonces por la derecha. En la elección para Presidente de 1999 el FA, presentándose como "Encuentro Progresista" (denominación ya usada en la elección anterior), ganó la primera vuelta con algo más del $40 \%$ de los votos y perdió la segunda con el $45 \%$ (merced por un lado a la unión de la derecha supuestamente separada en dos lemas desde hace más de 150 años, por otro lado, que es el mismo, a la reforma electoral auspiciada por esa misma derecha cuando en la elección anterior, aún en vuelta única, se hizo visible la posibilidad de victoria del FA, y, por último, y como era lógico esperar pues las familias son las mismas o emparentadas, al masivo respaldo que la radio y la TV dio a la derecha). En 1971 el FA decía a través de sus 'Bases Programáticas' cosas tales como: 'Lucha por una integración latinoamericana liberadora y acción conjunta para romper la dependencia política, económica, social y cultural... y ] solidaridad con todos los pueblos que luchan por liberarse de la opresión colonialista, neocolonialista e imperialista, especialmente con los latinoamericanos'; 'Negociar la reconversión de la deuda externa, postergando los pagos y eliminando sus condiciones leoninas, para destinar, durante el período necesario, toda la capacidad de ahorro nacional a las finalidades económicas y sociales de este programa [y] en caso de no obtenerse la reconversión, adopción de las medidas unilaterales necesarias para el logro de los fines enunciados'; se afirma la necesidad de la Reforma Agraria y de una 'política de nacionalizaciones [que] podrá tomar la forma de empresas estatales u otras...', con "nacionalización de la industria frigorífica" [ una de las principales del país ], 'nacionalización de la banca, de los grandes monopolios y de los rubros esenciales del comercio exterior...' y una 'participación decisiva del Estado en las industrias básicas no nacionalizadas'; se promete "fomento al cooperativismo...[con] mecanismos de integración y control que aseguren la defensa del carácter popular y progresista del sistema y eviten las posibilidades de su desvirtuación'. En 1999 la plataforma del FA se sintetizó en 76 iniciati- 
vas de diferente tono (llamadas "País Productivo" y presentadas en la ciudad de Salto el 10/09/1999, y en su esencia repetidas en los comicios nacionales de 2004 cuando alcanzó la victoria). En esas iniciativas, la óptica conciliatoria y aún empresarial se hace evidente cuando, por ejemplo, entre otras cosas se dice pensar en un país '...donde el empresariado privado sea el agente clave en el crecimiento económico y donde la cooperación entre empresarios y trabajadores y no la confrontación, posibilite un mejor crecimiento, más calidad de producción y un reparto equitativo de la riqueza'; más adelante se insiste en que " sólo a través de la cooperación [ entre empresarios y trabajadores] se logra un desarrollo productivo adecuado, nunca a través de la confrontación"; y se promete: '...una refinanciación [de deudas] que modifique los plazos de vencimientos para evitar ejecuciones que cuestionan la continuidad productiva de empresas que tienen la posibilidad de ser viables en un cuadro menos crítico [y] se suspenderán las ejecuciones en tanto se encara la refinanciación'. Cuando se habla de formas cooperativas de actividad, además de la recién citada 'cooperación entre empresarios y trabajadores'[!], el abordaje es también empresarial, como cuando se dice: 'Un capítulo especial merecerán las pequeñas y medianas empresas...a través del apoyo a la conformación de redes empresariales de cooperación, tanto para la compra de insumos y tecnología como para la comercialización final en el mercado interno y externo que potencien a escala, su capacidad competitiva'. La globalización capitalista es asumida tranquilamente cuando se promete que habrá "igualdad de tratamiento a las inversiones nacionales y extranjeras tanto instaladas como las que vengan a instalarse, [ en ] tanto se apliquen al cumplimiento de los objetivos estratégicos de la estrategia [sic, con bella redundancia!] productiva'. Y para redondear y a pesar de que la acción sindical uruguaya guiada por la Convención Nacional de Trabajadores (CNT) y su sucedáneo posdictadura, el Plenario Intersindical de Trabajadores (PIT-CNT), controlados desde siempre por la izquierda, ha sido tan reivindicativo-salarial como la brasileña, una de las 76 iniciativas dispone, asumiendo sin cor- 
tapisas el más rancio discurso capitalista, que el aumento de salario será vinculado al aumento de la productividad empresarial; en efecto, leemos que es una meta: 'estimular el crecimiento de los salarios en relación al crecimiento de la productividad de las empresas, para garantizar su competitividad'. [Ante tal gallarda afirmación se muere de vergüenza el análisis marxiano de la plusvalía relativa!, en El Capital, 1864-1874, Tomo I, Sección Cuarta ]. El capítulo de Medio Ambiente ocupa un parágrafo y sin rubores por su total contradicción con los criterios empresariales que nortean el conjunto de la propuesta dice, decretando sin explicar cómo se maneja el engendro del que no falta el concepto 'desarro$1 \mathrm{l}^{\prime}$, objeto de crítica hasta en filas centristas desde el Informe del Club de Roma 'Los límites del crecimiento' editado en 1972 (reproducido por Mesarovic en 1975): 'Es posible compatibilizar el desarrollo económico con la conservación del medio Ambiente en tanto los recursos ambientales, naturales y culturales constituyen parte vital del Patrimonio Nacional. Proponemos entonces que los proyectos deben ser ambientalmente sustentables, esto significa que deben ser: eficientes del punto de vista económico [ y se olvida la 'eficiencia' ecológica!], equitativos del punto de vista social [ ¿en medio a la división entre capitalistas y trabajadores?], conservacionistas del punto de vista de los sistemas involucrados [¿ bajo la lógica capitalista de la ganancia?], y, éticos del punto de vista de los derechos de las generaciones actuales y futuras [ ¿conviviendo con la ética del capital, que es la de la renuncia a la ética en pro de la ganancia a todo costo?] '. Ante tal galimatías parece claro que la encrucijada se define en los términos de la misma alternativa planteada a la izquierda brasileña: o hacer honor a las pretensiones poscapitalistas reasumiendo las preocupaciones de Guevara ('Táctica y estrategia de la revolución Latinoamericana', en Verde Olivo, 02/10/1968, en las Obras Completas de Guevara en dos tomos en Casa de las Américas de La Habana, 1970, p. 493 - 506, p. 505) en lo referente a la coherencia y continuidad entre táctica y estrategia, o adoptar con transparencia los límites de la prédica y la acción socialdemócrata al interior del capitalismo. 
En el mismo instante en el que el FA asumió el gobierno (o sea en marzo de 2005) expresé mis preocupaciones en el texto que sigue (aparecido en el n`1 de la revista 'Arjé', www.arje.uy.nu, editada en Montevideo). Allí decía, con el título 'NO PAGAR LA DEUDA AL PRECIO DEL HAMBRE DEL PUEBLO', “Apoyo las palabras pronunciadas por el Rector y por Tabaré Vázquez el 3 de marzo de 2005 en ocasión de la firma de un histórico acuerdo entre el gobierno nacional y la Universidad de la República, mediante el cual, nuestra máxima casa de estudios (sin ceder un ápice de su autonomía, así se dijo expresamente) se dispone a colaborar con el nuevo gobierno, en beneficio de la ciudadanía y del país, en áreas tan importantes como la creación y divulgación de conocimiento (incluyendo el de uso tecnológico-productivo inmediato), la educación, la salud y la defensa de los derechos humanos. (Desde nuestro cercano exilio universitario brasileño nos ponemos a las órdenes). Quizá la Universidad pueda también ayudar al Dr. Astori en materia de reflexión sobre la deuda externa. Astori dijo ese mismo día en conferencia de prensa que no veía por qué descartar la tradición creada de que los deudores negocien su deuda externa por separado y no se olvidó de pedir paciencia a los uruguayos. No se entiende por qué habremos de seguir prisioneros de una estrategia divisionista que los imperios (ahora el de EEUU) emplean desde siempre para dominar mejor a los sojuzgados; por qué, por ejemplo, el MERCOSUR habría de servir para todo y no para negociar conjuntamente la deuda? Que los "maestros" (siempre sumisos, cuando no funcionarios del FMI) de nuestros ministros latinoamericanos de economía no lo recomienden, es una cosa; pero desde cuando el pequeño Uruguay cree sacar ventaja negociando solito con el gigante yanqui? Por otro lado la Universidad podría recordarle a Astori que a esta altura, si se pretende de verdad atender a los más necesitados, el carácter impagable de la deuda externa no es ninguna cuestión ideológica (cualquiera que sea el sentido que se le de a esta palabra), sino rigurosamente matemática; si a un trabajador se le dice que no puede tocar la mitad de su salario (calculado para 
asegurar las necesidades básicas de su familia) porque esa suma ya está bloqueada para uso externo, NUNCA podrá ese trabajador satisfacer aquellas necesidades; si tira la frazada hacia arriba, sus pies quedarán a la intemperie, y si la tira hacia abajo quedará descubierta su cabeza. También se le podría decir a Astori que con la misma facilidad con la que pide paciencia a los necesitados uruguayos (sean personas o sistemas públicos de educación, salud o vivienda), podría ocurrírsele por una vez pedírsela a los supermillonarios acreedores, para quienes finalmente no es nada la friolera de 13.500 millones de dólares a que asciende la deuda bruta uruguaya (superando el PBI de 2004), y muchos menos los, para nosotros, impagables (si queremos atender a los más necesitados) intereses anuales de la misma. (Incluso podría aducir en un rapto de inspiración teológica, que hasta la Biblia reclama "perdonar nuestras deudas, como nosotros perdonamos a nuestros deudores"). Por último, no nos olvidemos que la mayor deuda que tenemos es la contraída con los compatriotas que el neoliberalismo (contrariando expresamente a Artigas) ha hecho cada vez más infelices: la economía debe servir al ser humano y nunca al revés. Si Perogrullo no es oído, entonces el gobierno descubrirá al cabo de uno o dos años otra verdad perogrullesca: el "timing" de los necesitados NO es el mismo que el que tenemos los sectores medios, de necesidades básicas resueltas; si con tan sólo poco más de 3 millones de habitantes y parte de las tierras más fértiles del mundo no se mejora rápida, tangible y sustancialmente la vida de la gente, entonces los movimientos y luchadores sociales descreerán del gobierno y entre el pueblo cundirá el desánimo; entonces llorarán otra vez las madres de tantos muertos y torturados que hicieron posible este gobierno, y es sólito que las urnas traigan de vuelta a los neoliberales que, como Vegh Villegas, proclaman a escondidas con orgullo: 'yo no soy pro-yanqui, soy yanqui'"'.

Como hasta fines del 2005 (y hasta hoy, octubre de 2007) el gobierno del FA no ha cambiado la política económica que sigue conduciendo su Ministro de Economía, Danilo Astori, un gru- 
Ecomunitarismo, reforma y revolución en América Latina: Uruguay hoy - Dr. Sirio Lopez Velasco

po de veteranos compañeros nos nucleamos en torno a uno de los primeros colaboradores de Raúl Sendic, Washington Rodríguez Belletti, para ayudar a quienes seguían bregando por construir nuevas formas solidarias y ecológicas de producción y de vida. A la primera reunión ocurrida en diciembre de 2005 llevé la siguiente PROPUESTA DE ACCIÓN ESTRATÉGICA EXTRAELECTORAL en URUGUAY: 1. No queremos depender de resultados electorales que quedan prisioneros de la deuda externa, el "riesgo país" y la "credibilidad ante los inversores", o sea, de la dependencia y la explotación; y tenemos la convicción de que un país con tan sólo 3,5 millones de habitantes instruidos y tierras fértiles, puede y debe encontrar soluciones para dar a los uruguayos una vida digna sin someterse a nadie. 2. El orden socioambiental utópico (nunca alcanzable pero indispensable guía para caminar) hacia el que queremos ir es el ecomunitarismo. En él se realizarían el lema "de cada uno según su capacidad y a cada uno según sus necesidades" y las tres normas éticas: a) cada uno decidiría libremente, b) cada uno lo haría en consenso y cooperación solidarios con los demás (desde el nivel local al planetario), y, c) se cuidaría permanentemente la salud de la naturaleza humana y no humana. 3. Con y más allá del actual gobierno del FA, se trata de organizar a todos aquellos que aceptando el ecomunitarismo como guía, quieran mejorar solidariamente la calidad de vida y promover la cooperación entre los pueblos, superando las taras del capitalismo y su expresión imperialista. 4. Se propone la acción "Vivir solidariamente en un Uruguay verde y feliz". 5. Esta acción se propone crear, preferentemente con personas que habitan hoy los cantegriles o rancheríos, cooperativas agroindustriales que den una vida feliz a sus integrantes, al tiempo que producen para el autoabastecimiento y el comercio, productos limpios desde el punto de vista ambiental (en especial, sin agrotóxicos u hormonas, sin métodos crueles en el trato con animales, y usando energías renovables y el ecoturismo). a) Las tierras se obtendrán gratis, porque recuperando la consigna "Por la tierra y con Sendic" y la lucha por la estancia de Silva y Rosas, esta ac- 
ción exigirá (si es necesario, con su ocupación) que le sean concedidas tierras de grandes estancieros crónicamente deudores del Banco República, en extensión correspondiente a lo adeudado. b) La financiación para la formación de los cooperativistas, la construcción de sus viviendas (dotadas de todas las comodidades urbanas) y locales laborales, la adquisición de máquinas e insumos y la producción, será exigida a los gobiernos nacional y municipales, al Banco República y otras agencias estatales, y solicitadas a Organizaciones No Gubernamentales internacionales o extranjeras interesadas en promover el "otro mundo posible" defendido por el Foro Social Mundial. La comercialización de la producción debe ser priorizada por el gobierno nacional (por ejemplo para abastecer los comedores populares y las meriendas escolares), y también será realizada a través de una red de suscriptores dispuestos a apoyar esta alternativa (recibiendo canastas semanales o mensuales), en ferias de productores orgánicos, e internacionalmente, con el "sello verde", a quien desee comprarla. La asesoría técnica será solicitada a estudiantes universitarios y de UTU que deseen colaborar (recibiendo becas para ello). Se luchará para que la Universidad de la República implante una Facultad (según elección de la población del Departamento) en cada capital departamental. 6. Nótese que esta acción: a) da vida digna a personas (en especial jóvenes) que hoy carecen de horizontes, b) corrige la absurda concentración demográfica en las ciudades (insana desde todo punto de vista, en especial en lo relativo a la violencia), en un Uruguay que siempre ha vivido de su campo, c) aprovecha nuestra alta capacidad técnico-universitaria, d) crea redes solidarias con gentes y pueblos, favoreciendo así la paz mundial, f) frena la emigración juvenil, g) integra la acción de muchos Ministerios (en especial MGAP, Educación, MIDES, MSP, y Vivienda y Medio Ambiente), y, h) nos reconcilia a los humanos y con la naturaleza no humana. Y concluíamos: Para seguir plantando esta alternativa, HACEMOS NUESTRA LA LUCHA POR LA TIERRA, ENCABEZADA POR LOS PELUDOS DE BELLA UNIÓN. 
Ecomunitarismo, reforma y revolución en América Latina: Uruguay hoy - Dr. Sirio Lopez Velasco

Esta frase final aludía a la primera ocupación de tierras que un grupo de familias de trabajadores cañeros preparaban en el extremo norte uruguayo, y que evolucionó de la manera que relataremos en lo que sigue.

\section{Ecomunitarismo y lucha por la tierra en Uruguay: un pequeño-gran triunfo}

A fines de los años 50 e inicio de los 60 del siglo pasado, Raúl Sendic Antonaccio, ayudó a trabajadores rurales uruguayos de la remolacha, del arroz y de la caña de azúcar, a fundar sindicatos y luchar por los derechos laboristas fundamentales; simultáneamente defendió junto a ellos la necesidad de una reforma agraria que repartiese los inmensos latifundios uruguayos que monopolizaban (y monopolizan) en manos de pocas centenas de familias la propiedad de la mayor parte de las tierras del país. Entonces se fundó UTAA (Unión de Trabajadores Azucareros de Artigas), quien desde Bella Unión, en el extremo norte del país, protagonizó varias marchas de hombres, mujeres y niños hasta Montevideo, con las consignas "Por la tierra y con Sendic", "Tierra para quien la trabaja" y "Tierra y libertad"; esas marchas y la represión policial encendieron la conciencia de toda una generación de jóvenes (en especial estudiantes liceales y universitarios) que se asomaba a la actividad política por aquellos tiempos. Ante el aumento de la movilización popular (la unitaria Convención Nacional de Trabajadores fue creada en 1966) y la intransigencia de la oligarquía latifundista-industrial-bancaria (asociada al imperialismo yanqui que ya imponía en A. Latina su Doctrina de Seguridad Nacional, a partir del golpe en Brasil en 1964), que se aprestaba a defender sus privilegios por la fuerza de un Golpe de Estado, Sendic funda junto a una docena de compañeros el Movimiento de Liberación Nacional - Tupamaros (MLN) para practicar la lucha armada en las condiciones predominantemente urbanas de Uruguay, buscando la liberación nacional y el socialismo. Rápidamente tiene que pasar a la clandestinidad y el MLN empezó a crecer imparable. A él nos integramos con tan sólo 17 años 
(para trillar una trayectoria que describimos en nuestro más reciente libro "Alias Roberto: diario ideológico de una generación", Ed. Baltgráfica, Montevideo, 2007). El año 1971 vio nacer al Frente Amplio, que congregó a casi toda la izquierda uruguaya (desde demócrata-cristianos hasta trotskistas, pasando por comunistas y simpatizantes del MLN) para presentarse a las elecciones de fines de año. Un fraude electoral llevó al gobierno a uno de los hombres del partido Colorado menos dotado intelectualmente y más comprometido con los EEUU y la oligarquía uruguaya. La represión no cesó de aumentar e incluyó la acción de un Escuadrón de la Muerte auspiciado por los EEUU y formado por militares y policías. En abril de 1972 el MLN ejecutó a algunos integrantes de ese Escuadrón, y las Fuerzas Armadas, respondiendo a un plan elaborado de antemano, asumieron el rol protagónico de la represión, para ir ocupando cada vez más espacio político, hasta proclamar el Golpe de Estado abierto en junio de 1973. Sendic y todos los dirigentes históricos del MLN habían sido encarcelados y sometidos a torturas sistemáticas durante meses y años (y algunos de ellos, así como muchos militantes del MLN y/o del Frente Amplio, fueron asesinados, y otros aún están desaparecidos). El pueblo resistió durante 15 heroicos días al Golpe de Estado; pero sin poder militar para hacer frente a las Fuerzas Armadas, tuvo que ceder. Y una larga dictadura se instaló en Uruguay hasta 1985 (no sin que durante todo ese lapso el pueblo uruguayo dejara de resistirle, como lo hizo al derrotarla en el Plebiscito Constitucional que la misma había convocado en 1980). Como a otros compañeros, en la inminencia del Golpe o tras él, el MLN nos ordenó salir del país para volver mejor organizados; nos reagrupamos primero en el Chile de Allende y luego en Cuba; tras una división y cuando volvíamos al Río de la Plata, una decisión de la Dirección nos hizo asilarnos en Europa. En Bélgica aproveché a estudiar y me doctoré en Filosofía (además de licenciarme en Lingüística). Entonces empezó la reelaboración de las ideas que nos habían llevado al compromiso político. Con el tiempo fue madurando mi obra original: la ética argumentativa ecomu- 
Ecomunitarismo, reforma y revolución en América Latina: Uruguay hoy - Dr. Sirio Lopez Velasco

nitarista (ver su versión simplificada para el gran público en "Ética para mis hijos y no iniciados", Ed. Anthropos, Barcelona, 2003). Básicamente propongo: 1) que las normas éticas sean entendidas como Casi-Razonamientos Causales en los que un enunciado falseable sirve de soporte a la legitimidad ("felicidad", digo con John L. Austin) del obligativo que la precede; así una norma ética tiene la forma "Debo x porque E". Investigando las condiciones de "felicidad" de la pregunta que instaura la ética, a saber "¿Qué debo hacer?" descubro tres normas éticas fundamentales de valor intersubjetivo universal: a) la primera nos obliga a luchar por realizar nuestra libertad individual de decisión, b) la segunda nos obliga a realizar esa libertad consensualmente (o sea, con la libertad de los otros y no contra ella), y, c) la tercera nos obliga a preservar-regenerar una naturaleza (humana y no humana) sana. Después de mostrar que el capitalismo viola cotidianamente esas normas, postulo que ellas serían realizadas en un orden poscapitalista que denominé "ecomunitarismo" (nunca plenamente realizable y de carácter utópico, pero indispensable guía para la acción, a los efectos de no perder el rumbo). Del ecomunitarismo hace parte una economía ecológica que en el campo se articula en cooperativas agroindustriales que practican una producción sustentable (en especial con agricultura orgánica, apoyada en los recursos renovables, inspirada en las " $3 \mathrm{R}$ " que son 'reducir, reutilizar y reciclar' recursos y residuos, y volcada a hacer realidad la consigna 'de cada uno según su capacidad y a cada uno según su necesidad'). En marzo de 2005 el Frente Amplio conquistó por primera vez el gobierno nacional en Uruguay, con goce de mayoría parlamentaria; pero la reforma agraria soñada por Sendic y que complementamos con nuestra visión ecomunitarista, no hacía parte de la agenda gubernamental. Entonces, inspirándonos de la Plataforma del Movimiento por la Tierra y contra la Pobreza elaborada por Sendic al salir de la cárcel en 1985 (para morir poco tiempo después a causa de una rara enfermedad asociada a las torturas sufridas), a fines de 2005 nos nucleamos alrededor de Washington Rodríguez Belletti, viejo compañero de Sendic, para 
apoyar la ocupación por parte de trabajadores cañeros y sus familias de un predio de 32 hectáreas situado en Bella Unión (al extremo norte uruguayo, donde Sendic había fundado UTAA), cedido por el Instituto Nacional de Colonización a un falso colono que allí no residía ni plantaba nada hacía años. (Nota: en julio de 2007 una multinacional de la forestación de monocultivos para la celulosa declaró que tiene en Uruguay ciento sesenta mil hectáreas). El 15 de enero de 2006, con el apoyo de nuestro núcleo y otras organizaciones sociales, sindicales y políticas, tuvo efecto la ocupación (de cuya coordinación participaba un viejo ayudante de Sendic que durante la dictadura había purgado 12 años de prisión por su militancia en UTAA y en el MLN). La iniciativa pretendía relanzar el Proyecto de Recolonización Agraria, que proponía el asentamiento de 100 familias en 1200 hectáreas de la zona, presentado ante distintas autoridades en el año 1997. En el 2005 el gobierno crea el proyecto sucro-alcoholero que se plantea a través de la empresa estatal ALUR (Alcoholes del Uruguay) la recuperación de áreas de caña de azúcar que habían disminuido de 9000 hás. a 3000 hás. en la zona, y proyectaba en los próximos 5 años llegar a las 10.000 hectáreas de caña, utilizando y mejorando la importante infraestructura del lugar, destinando el producto a la fabricación de azúcar y luego a la elaboración de alcohol combustible. Pero los ocupantes señalaron que "La adjudicación de créditos para los grandes productores ha sido denunciada por las organizaciones de trabajadores que reclaman ser agentes de la inversión del gobierno creando cooperativas de trabajadores dedicadas al cultivo de la caña de azúcar y la producción de alimentos, para dejar de ser excluidos de tal oportunidad". La ocupación, constituida en la Cooperativa "15 de enero" se planteó los siguientes objetivos: a) Objetivo General: Impulsar la producción sustentable de alimentos como fuente de ingresos y subsistencia de 15 familias de trabajadores rurales organizados, de la zona de Bella Unión; complementar así la producción cooperativa de caña de azúcar que llevan adelante organizaciones de asalariados rurales y pequeños productores desde el pasado 15 de enero de 
Ecomunitarismo, reforma y revolución en América Latina: Uruguay hoy - Dr. Sirio Lopez Velasco

2006, en el marco del emprendimiento sucro-alcoholero del gobierno nacional, b) Objetivos Específicos: 1) Invertir en la infraestructura necesaria para llevar adelante la producción vegetal y animal que viabilice el proyecto de sustentabilidad alimentaria; 2) Impulsar la comercialización de la producción alimentaria en los mercados locales, a buen precio y con condiciones sanitarias garantizadas; promover la industrialización a pequeña escala de los derivados del azúcar; 3) Promover la capacitación técnica y organizativa de trabajadores organizados. Y definió el siguiente Plan de Actividades: Creación de huerta y cría de animales para autoconsumo y venta de excedentes. Se llevaría a cabo el plantío de algunas hás. de caña de azúcar para ALUR y para semilla; en la horticultura habría Papa, Cebolla, Arveja, Chícharo, Habas, Ajo, Zanahoria, Porotos, Maní, Chaucha, Boniato, Maíz Dulce, Maíz Cuarentino, Maíz para grano, Sorgo granífero y forrajero, Pepino, Zapallos y zapallitos, y Cultivos de Hoja (Acelga, Lechuga, Perejil, entre otros), además de arroz para el autoconsumo; y 2000 mts. ${ }^{2}$ de invernáculo con morrón, tomate, zapallito. Además habría algunas hás. de avena, para cobertura y mejoramiento del suelo y, alimentación de vacas lecheras; y plantío de pastura permanente con 2 há. de pradera (tréboles, festuca, alfalfa, etc.) de prueba para mejoramiento de suelo, alimentación de ganado e incorporación de rotaciones largas al sistema productivo de caña. Para tanto se consumirían 120 toneladas de abono orgánico y, en especial para la caña habría "uso racional de agrotóxicos". Como producción animal se criarían : 7 vacas lecheras para el consumo de las familias responsables del emprendimiento productivo, $\mathrm{y}$ 200 gallinas doble propos. Además se preveía: a) La promoción de Canales de Comercialización e industrialización casera de la producción de caña ( transporte para la comercialización en el mercado local, en dos ciclos, y la industrialización casera de la caña de azúcar, utilizando maquinaria de pequeña escala), y, b) La implementación de una escuela de formación para trabajadores y agricultores minifundistas, fomentando la capacitación técnica para la producción animal y vegetal, con cursos de alfabetización 
con el método cubano "Yo Sí Puedo" durante todo el año, y Talleres de autogestión y cooperativismo con trabajadores rurales también durante todo el año. Inmediatamente después de la ocupación y de conocidos los planes de la Cooperativa, los latifundistas, a través de su entidad (la Asociación Rural del Uruguay) presionaron al gobierno para que se los expulsase y castigase ejemplarmente, a fin de proteger la propiedad privada y "la paz" (su "paz") en el campo. El juez actuante le dio largas al asunto, estudiando la queja del ex-colono, y los ocupantes comenzaron (con los menguados recursos que la solidaridad sindical, social y política podía hacerles llegar) a poner en marcha parte de su plan productivo; tarea nada fácil pues debían alojarse debajo de carpas, sin luz eléctrica ni (en los primeros meses) agua potable. Varias veces algunas autoridades exigieron la retirada de los ocupantes a cambio de supuestas mediaciones y soluciones; pero los ocupantes se mantuvieron firmes en la trinchera y la producción, y a fines de julio del 2007 (tras un año y medio de lucha) la Justicia determinó la cesión del predio a ALUR, quien a su vez se lo cedió a los ocupantes para que, junto a la labor productiva, sea escenario de aquella escuela de formación propuesta por la cooperativa.

El sueño ecomunitarista ha ganado otra batalla. (Pero la lucha nunca cesa, pues poco antes de este feliz medio-final, el parlamento uruguayo había votado, con los sufragios de la bancada del Frente Amplio, una nueva ley que castiga con hasta 3 años de cárcel la ocupación de inmuebles; la Cooperativa "15 de enero" se ha puesto a la vanguardia de la campaña por la derogación de esa ley).

\section{El balance del presidente Vásquez a la mitad del camino}

El presidente uruguayo, Tabaré Vázquez realizó el 07/09/2007 en cadena de radio y TV un balance muy positivo y nada autocrítico de sus primeros 30 meses de gobierno, o sea de la mitad 
de su mandato (ver La República, 08/09/2007). Copió casi letra por letra expresiones que usó Lula al fin de su primer mandato, al decir que había advertido "que los problemas del país eran de tal gravedad que no podían solucionarse de inmediato ni por la sola voluntad del gobierno, que se necesitaban cambios estructurales profundos, y que esos cambios requerían tiempo y apoyo de la sociedad", y que ya como candidato había aclarado que " Si alguien cree que votándonos a nosotros todo mejorará de la noche a la mañana, por favor, ....que no nos vote...", y usó la misma comparación de un spot televisivo de la propaganda de Lula al llegar al gobierno (y empezar por la Reforma de la Previdencia Social, retirando derechos a los jubilados del sector público) cuando expresó que en vez de limitarse a "pintar la fachada de la casa", se abocó a "una reforma estructural de la casa, comenzando por sus cimientos y respetando los pilares fundamentales de la construcción, en este caso del país, de nuestra institucionalidad democrática: la Constitución de la República y las normas legales vigentes", por lo que estaría "recimentando y reestructurando la casa, con las dificultades y los inconvenientes que a veces ello genera a sus habitantes", en una acción que "lleva tiempo, que es cara, que no luce, pero convencidos de que es la mejor opción". Y luego, entre otras cosas: a) aseguró que en lo que resta de su mandato el Uruguay Productivo será la gran preocupación del gobierno, en tanto "contexto macroeconómico estable y favorable a la inversión productiva", por lo cual aseguró que "no habrá cambios en la política económica", b) afirmó que el gobierno encara una reforma estructural del país, comenzando por los cimientos y respetando los pilares fundamentales de la institucionalidad democrática que son la Constitución y las normas legales, c) dijo, refiriéndose al incremento de precios de algunos productos de la canasta básica familiar que "La suba de precios no es un drama, no hay una hiperinflación, sino un empuje que comenzó hace varios meses y que se debe a varios factores, algunos externos y otros internos, como fenómenos climáticos adversos y mayor demanda porque la gente trabaja más y consume más", y reafir- 
mó que se tomarán todas las medidas de tipo financiero que se requieran, y que no dudará en adoptar las iniciativas necesarias para controlar lo que calificó como un "impuesto a los pobres"; subrayó que tal incremento en los precios "no se debe a la entrada en vigencia de la Reforma Tributaria, ya que sin el nuevo sistema el aumento de los precios hubiese impactado más duramente en la economía y en especial en toda la gente"; d) ante la renuncia en masa de los anestesistas del servicio público de salud por su inconformidad (compartida por otros sectores médicos) con

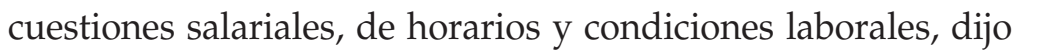
"Todos somos importantes pero nadie es imprescindible", y "El gobierno garantiza plenamente la asistencia de toda la ciudadanía tanto en Salud Pública como en el esquema general de salud de todo el país", e) evaluó que durante los dos años y medio de su gestión "disminuyó el monto y mejoró el perfil de la deuda pública", que aumentaron los activos de reservas de U\$S 2.265 millones a U\$S 3.539 millones y destacó que el aumento del PBI pasó del 6,6\% en 2005 al 7\% en 2006, a lo cual debe agregarse, dijo, "la expansión de la inversión bruta interna en un 16\% (que no se debe toda a la multinacional del monocultivo forestal y la celulosa Botnia, aclaró) y el comercio exterior con exportaciones de bienes y servicios que llegan a los U\$S 6 mil millones anuales, f) a la vez, resaltó que el gasto social del Estado pasó del " 40 al $49 \%$ ", dijo que se registró un descenso en la pobreza de 31.9\% en diciembre de 2004 a $24.3 \%$ en diciembre de 2006, y en igual período la indigencia cayó del 3.9\% al 1.4\%; “Uruguay tiene 50 mil indigentes menos y 300 mil pobres menos que los registrados hace dos años y medio", dijo Vázquez; g) refiriéndose a la lucha contra la "desocupación y por la creación de puestos de trabajo genuinos", sostuvo que "el desempleo descendió del 13\% en diciembre de 2004 a 9.7\% en el tercer trimestre móvil de 2007, mientras que la tasa de empleo creció del 50,8\% a 56,5\%, lo que se traduce en 162.500 nuevos empleos"; h) el gasto previsto para el presupuesto, "entre 2004 y 2006 aumentó en más de U\$S 1.400 millones", y enfatizó que para 2007 y 2008 se aprobaron incre- 
Ecomunitarismo, reforma y revolución en América Latina: Uruguay hoy - Dr. Sirio Lopez Velasco

mentos presupuestales de $\$ 2.800$ millones $\$ 3.400$ millones respectivamente, en un esfuerzo sostenido que permite aproximarse a la meta trazada de alcanzar el 4.5\% del PBI para la educación; i) Vázquez dijo que en el período 2005 - 2007, las exportaciones uruguayas al mundo pasaron de "U\$S 3 mil millones a U\$S 6 mil millones", j) por otro lado, indicó que existió "un fuerte impulso para que el Banco de la República Oriental del Uruguay redujera el número de morosos, que en un $61 \%$, mediante cancelación o convenios de pago resolvieran su situación", y, además, se creó un fideicomiso entre el Banco y el Ministerio de Ganadería Agricultura y Pesca para atender con créditos y garantías a los dueños de tierras deudores en hasta U\$S 50 mil (suma que luego aumentó hasta US\$250.000); k) Vázquez también se refirió a los avances logrados en materia de derechos humanos y dijo que la voluntad del gobierno es "seguir trabajando en la memoria, porque es una necesidad del alma humana, en la verdad, que es el único camino para superar las heridas, y en la justicia, que no es revancha ni desconocimiento de la legislación vigente".

Ante tal balance, incluso Alberto Couriel, senador del FA y economista moderado, si bien destaca los méritos de ciertos números presentados por Vázquez en lo relativo a la disminución de la indigencia y la pobreza, la creación de empleos, la mejora del salario, el crecimiento del PBI y el descenso de la mortalidad infantil, considera que de esa política económica adoptada hasta ahora y que el Presidente dijo que no cambiará, hacen parte de la ortodoxia neoliberal recetada por el FMI y las calificadoras de riesgo: a) el estricto cumplimiento del pago de la deuda externa y la atención prioritaria de la estabilización de precios, como formas que conseguir la mejor relación posible con el mercado financiero internacional, en la suposición de que el sector privado y el mercado van a lograr el crecimiento y mejora del empleo sin que se requiera la intervención del Estado a través de políticas activas, sectoriales y selectivas, b) la política monetaria y cambiaria (de libre flotación), c) la disminución de la presión fiscal sobre los empresarios y la implementación de una reforma tributaria que 
trata con más benevolencia a las rentas del capital que a las del trabajo, d) la política monetarista del Banco Central para atacar la inflación, y, e) la propuesta de dar "autonomía" a dicha institución, pues, sabemos, agrego, yo, que tal "autonomía" se refiere a las instancias nacionales influidas por el voto popular, y no a las directrices del FMI, el BM y los EEUU, de las que mantendría total dependencia (La República, Montevideo, 12/09/2007).

\section{La alternativa de masas}

El 14 de setiembre de 2007 se instaló la fase preparatoria del $2^{\circ}$ Congreso del Pueblo, con la consigna de "profundizar los cambios"; el primero, convocado en 1965 por diversas organizaciones sindicales, sociales y políticas, culminó con la unificación del movimiento obrero uruguayo (que dio origen a la unitaria Convención Nacional de Trabajadores). Ahora, entre los convocantes figuran la CNT (rebautizada tras la dictadura PIT-CNT), la Universidad de la República, la Federación de Estudiantes Universitarios del Uruguay (FEUU), la Federación Uruguaya de Cooperativas de Vivienda por Ayuda Mutua (Fucvam), y el Servicio de Paz y Justicia (Serpaj), además de dos agrupaciones de música carnavalesca (en Uruguay llamadas "murgas", y en general muy críticas en su repertorio), Araca La Cana y El Gran Tuleque, y el apoyo de intelectuales y artistas entre los que cabe citar a Eduardo Galeano. Los primeros trabajos definieron a la integración latinoamericana como uno de los ejes de reflexión y acción del $2^{\circ}$ Congreso del Pueblo. Y en lo que hace a la política uruguaya, tras el debate de los tres talleres que tuvieron como cometido presentar ideas, propuestas o reivindicaciones para ser analizadas en próximas reuniones por la comisión preparatoria del Congreso, se destacaron en especial: la elaboración de una Reforma Agraria, analizar el fenómeno de la extranjerización de la tierra (cifras oficiales muestran que el 10\% de la tierra uruguaya está en manos extranjeras y que ese porcentaje se duplica en las áreas de frontera), evaluar el no pago de la deuda externa, la defensa de las empresas públicas, nacionalizar la minería, impul- 
sar una justicia tributaria más equitativa que la actual, crear una asamblea constituyente, control estatal del agua, la tierra, la semilla y la producción, derogar las AFAP (instituciones privadas de previdencia social), reducir la jornada laboral para generar más mano de obra, cambiar la base monetaria, construir viviendas para los productores rurales, levantar el secreto bancario, $\mathrm{y}$ la creación de un Instituto Nacional de Derechos Humanos. En el marco de estas propuestas, también se presentaron cuatro preguntas: ¿Quién fijará el Salario Mínimo Nacional? ¿Qué seguridad social quieren los uruguayos? ¿Qué necesitan reclamar las organizaciones sociales? Y por último, ¿qué está mal en la actual política económica?

Insertada en esa alternativa de masas y a la vez paralelamente a ella, es posible que surja una reorganización política de viejo o nuevo tipo (o sea partidaria-electoralista, o bien, políticomilitar clandestina) que, inspirada por Cuba y Venezuela, intente llevar los cambios inaugurados por el FA rumbo a un horizonte poscapitalista (el socialismo del siglo XXI, al que hemos denominado el "ecomunitarismo").

\section{Conclusiones y perspectivas: nuestra visión}

En las páginas precedentes hemos destacado los méritos que nos han parecido más relevantes en la gestión nacional del FA en lo que se refiere a la atenuación de ciertas de las aristas más inhumanas del capitalismo (como lo es la indigencia), a la vez que hemos cuestionado algunos de los supuestos méritos de una política económica que (a atenerse incluso por las reiteradas felicitaciones del FMI y del Banco Mundial) continúa la senda neoliberal; al respecto dijo Vázquez en su discurso que hay un "contexto macroeconómico estable, transparente y favorable a la inversión productiva, [y] en tal sentido, y para decirlo "cortita y al pie": no habrá cambios en la política económica; no habrá cambios"; ahora, hago notar yo que en nada interesa a los pobres (que son más que los indigentes atendidos, y sólo en lo más urgente, por el 
Plan de Emergencia) el aumento del PBI, de las reservas internacionales, de las exportaciones y de la inversión extranjera, si ello no se traduce en una notoria elevación de la calidad de vida de esos sectores (recordando que tras 36 años de creación del FA, el "tiempo de espera paciente" de los pobres generados por el capitalismo ya se agotó y su expectativa de cambios rápidos y visibles es más que justificada; y que no basta hablar del ingreso medio de los hogares, que según Váquez creció un 13\% durante el 2006, pues ya sabemos que en la estadística de las medias de dos personas, cada uno come dos pollos cuando uno come cuatro y el otro ninguno); y, agrego yo, en nada nos acercamos al poscapitalismo, si el llamado "aumento del empleo" significa la creación de trabajo alienado-explotado, sin que aumente significativamente la parte que en la economía tienen los emprendimientos cooperativos solidarios y ecológicos; por otro lado es significativo que se tarde tanto en alcanzar la meta del 4,5\% del PBI para educación, (recordemos que la ONU exige el 6\%) cuando se garantiza religiosamente ese porcentaje de superavit fiscal para el pago cronométrico de la deuda externa; sobre la Reforma Tributaria, se ha mostrado que ella recauda sólo $9 \%$ entre los capitalistas y $80 \%$ entre trabajadores y jubilados. En el terreno agrario, si se implementa una refinanciación para los deudores de hasta 250 mil dólares con los Bancos públicos (ley firmada por Vázquez el 10/09/2007), no se expropia por el valor de su deuda, para poner sus tierras al servicio de las cooperativas solidarias y ecológicas que propugnamos, a los de macro-deudores contumaces, y algunos números de la situación agraria en Uruguay muestran: a) que en el año 2000, las 57.000 explotaciones rurales existentes apenas proporcionaban empleo a un total de 157.000 trabajadores, b) el $63 \%$ de los predios de menos de 100 hectáreas, ocupan tan solo el $6 \%$ de la superficie, mientras que el $60 \%$ de ésta es explotada por apenas el $7 \%$ de los grandes propietarios de más de 1.000 hectáreas, y, c) en los 12 años que van de 1988 al 2000, 500 millones de dólares fueron desembolsados por el Estado uruguayo para subsidiar al monocultivo forestal (Datos de la Comisión de 
Ecomunitarismo, reforma y revolución en América Latina: Uruguay hoy - Dr. Sirio Lopez Velasco

Apoyo a la lucha por la Tierra, CAxTierra, de setiembre de 2007). Por último, las organizaciones más representativas de DDHH en Uruguay (entre ellas la Plenaria Memoria y Justicia) siguen reclamando que se haga justicia con los torturadores más notorios de la dictadura, y en la primera semana de setiembre de 2007, por iniciativa de esas organizaciones, apoyadas por otras de la esfera sindical, social y política, y no por iniciativa del gobierno, se lanzó la recogida de firmas (hacen falta 250 mil en un país cuya población total es de 3,5 millones de habitantes) para convocar a un referéndum que derogue la llamada Ley de Impunidad (similar a la de Punto Final en Argentina), que, para dejar impunes a los personeros de la dictadura "renunció (en esos casos) a las prerrogativas punitivas del Estado" (sic!)

Por nuestra parte propugnamos: a) la realización de un Plebiscito para que el pueblo apoye al gobierno en la conquista de una drástica reducción del pago de intereses de la deuda pública externa, o su cambio por inversiones, determinadas soberanamente por el gobierno nacional, en las áreas de economía cooperativa, educación, salud, vivienda popular y medio ambiente), b) priorizar la generación de fuentes de trabajo cooperativo (y no las inversiones privadas que significan más explotación y más dependencia), con el necesario apoyo estatal, en actividades ecológicamente sostenibles c) apostar macizamente a la educación ambientalizada pública y productiva (desde jardinera a la Universidad), descentralizando la educación superior y dotando al campo de Escuelas Secundarias que combinen estudio y producción, d) practicar la democracia participativa, siempre que posible en forma directa (perfectamente posible, con presencia física o a través de Internet, en un Uruguay que no sobrepasa los 3,5 millones de habitantes), desestatizando y desburocratizando la sociedad con la acción de las organizaciones de la sociedad civil, apoyadas por las ONG's, e) reducir progresivamente el tiempo de trabajo para que cada individuo pueda realizarse multilateralmente según sus vocaciones, f) mantener a costa de fondos públicos a los ancianos y aprovechar productivamente, (en régimen 
de voluntariado) su enorme experiencia de vida, g) integrar al Conosur, a América Latina y al planeta con el espíritu de Artigas, Bolivar y Ernesto Guevara. Por eso pedimos la salida de la "línea Astori" del Ministerio de Economía y su sustitución por la del OTRO país posible y necesario.

Y a fines de 2007 esa lucha continúa siendo necesaria, pues, a pesar de la disminución de la miseria extrema a través del Plan de Emergencia instrumentado por el Ministerio de Desarrollo Social, a pesar de ciertos avances en la legislación del trabajo, a pesar de la gestión participativa desarrollada desde 2005 en Montevideo por nuestro ex-compañero de MLN, el Dr. Ricardo Ehrlich, la política macro-económica heredada de la derecha no se ha alterado (como lo demuestra el hecho de que en el Impuesto a la Renta implantado por el gobierno del FA en 2007, los capitalistas pagarán sólo el $9 \%$ de lo recaudado mientras que los trabajadores y jubilados contribuirán con el 80\%, al tiempo que sigue sin existir un impuesto que grave a los latifundios, $\mathrm{y}$, en especial a los de las multinacionales del monocultivo forestal), y no hay atisbos de cambios profundos hacia el poscapitalismo (o sea, hacia el ecomunitarismo).

\section{La gestación de la nueva ley de educación en Uruguay}

Después de la victoria presidencial del Frente Amplio, acompañada con la obtención de la mayoría absoluta en el Parlamento, y confirmada meses después con la victoria en las elecciones municipales en varios Departamentos donde vive las tres cuartas partes de la población uruguaya, en Uruguay se abrió la esperanza de una nueva Ley de Educación que recoja las expectativas transformadoras en perspectiva soberanista y de liberación.

En ese contexto la Unidad Temática de Educación del Frente Amplio (que congrega a docentes que desde hace más de 30 años reflexionan y luchan por la educación pública, gratuita, de 
Ecomunitarismo, reforma y revolución en América Latina: Uruguay hoy - Dr. Sirio Lopez Velasco

calidad y comprometida con los más necesitados) elevó al gobierno a mediados del 2005 una propuesta para el proceso de construcción de esa nueva Ley que pedía: a) que la misma sea gestada en un gran proceso congresal, b) que, coordinada por una Comisión, la discusión abarcase a cada Escuela, Liceo y Facultad a lo largo y ancho de toda la república, c) que la síntesis del texto final fuera realizada en una Asamblea Nacional, y, d) que ese sea el texto que el Gobierno envíe al Parlamento, esperando su homologación. Convergiendo con esa propuesta (que recoge y amplía la experiencia de la Constituyente Escolar vivida en Rio Grande do Sul, Brasil, durante el gobierno de Olívio Dutra en 1999-2002) habíamos planteado antes las siguientes sugerencias, esperando verlas incorporadas en el proceso de construcción de la nueva ley. 1) La educación infantil, primaria, secundaria, universitaria, técnica, especial y permanente es un derecho de todos los que habiten suelo uruguayo y deber del Estado, quien la ofrecerá gratuitamente; la educación infantil, primaria y secundaria es obligatoria hasta los 18 años. 2) Se creará de inmediato en cada capital Departamental por lo menos una Facultad (en área a determinar según la demanda local) subordinada a la Universidad de la República pero con cuerpo docente propio y permanente, financiada por los gobiernos nacional y municipal. (Nota: Los Liceos públicos Departamentales fueron creados ya hace 100 años, en 1912-1913, y hoy, lo mínimo que cada Departamento puede pedir-esperar en materia de enseñanza superior es una Facultad permanente). 3) Se elaborará una Base Común Nacional para la formación de educadores que contemple la combinación teoríapráctica, el trabajo interdisciplinario, el compromiso democrático y la "ambientalización" de la enseñanza-aprendizaje. 4) Se propugnará en la formación de docentes y en el trabajo educativo diario, la moderna pedagogía problematizadora, vinculando los temas a problemas socio-ambientales relevantes del Uruguay, A. Latina y del mundo, desarrollándolos mediante la investigación científica imbuída de compromiso ético, y apuntando a la solución de aquellos grandes problemas. 5) Los Directores de Escue- 
las y Liceos serán elegidos mediante votación por los docentes, funcionarios, alumnos y padres de alumnos vinculados al respectivo establecimiento, entre los candidatos que, poseyendo la calificación exigida por ley, presenten su candidatura para ese cargo. (Nota: Esa experiencia funciona en Rio Grande do Sul, Brasil, ya hace casi una década con buenos resultados). 6) Se instituirá/ampliará un Programa de Becas que cubra todos los niveles/modalidades de la educación destinado a auxiliar en especial a alumnos carenciados de las periferias urbanas y del campo. 7) La Universidad de la República (y la enseñanza pública en general) será financiada por el Estado mediante porcentaje fijo del PBI o del Presupuesto (con mínimo irreductible según el ejercicio inmediatamente anterior) y gozará de plena autonomía financiera, didáctico-científica y administrativa; se creará el Consejo Comunitario Consultivo, integrado en mayoría por representantes de los sindicatos y organizaciones no-gubernamentales, que evaluará y sugerirá actividades universitarias que beneficien a los sectores más carenciados, a la preservación-regeneración del medio ambiente y al país. 8) Todos los niveles de la educación tendrán actividad productiva vinculada a la agricultura, ganadería, industria, servicios, salud o medio ambiente. 8a. Se crearán en tierras debidas por latifundistas morosos con el Banco República, Escuelas Secundarias Básicas en el Campo, cuyos alumnos, en régimen de (semi)internato cuidarán, con el auxilio técnico de la Universidad de la República, de la UTU y de otros centros públicos de asesoría, de las producciones más propicias según el suelo y el lugar, destinadas a contribuir al auto-costeo de la Escuela, a la sobrevivencia de sus familias y a la economía del país. (Nota: En Cuba hace por lo menos 35 años todas las grandes plantaciones de cítricos dependen de esas Escuelas). 9)Las ayudas económicas y asesorías internacionales siempre se subordinarán a las decisiones pedagógico-administrativas de las autoridades uruguayas de la educación y de los organismos representantes de los docentes, técnicos y alumnos. 
Ahora bien, se puede preguntar, ¿como financiar todo eso? Helios Sarthou (profesor grado 5 de Derecho en la Universidad de la República del Uruguay) en texto publicado en Montevideo en 2005 (La República del 26/06/2005) afirma que Uruguay tiene derecho a no pagar la parte de la deuda externa pública contraída por la dictadura e invocando urgentes necesidades sociales, amparándose en la Convención de Viena y en el Pacto Internacional de los Derechos Económicos, Sociales y Culturales (Pidesc). Tales instrumentos podrían dar base a los negociadores uruguayos, apoyados por el Plebiscito popular que hemos propuesto sobre el pago de la deuda externa, para canjearla en parte por esas inversiones en educación.

Durante varios meses de 2006 se impulsó simultáneamente por el gobierno y por los profesionales de la Educación un amplio Debate Nacional que culminó en un gran Congreso cuyos documentos conclusivos hicieron eco al espíritu de algunas de las ideas que avanzábamos (incluyendo la creación de una Universidad Nacional Pedagógica Descentralizada). No obstante, al día de hoy (octubre de 2007) el gobierno aún no ha elevado al Parlamento el pre-proyecto de la nueva Ley de Educación, y esperamos que cuando lo haga, su texto no traicione las ideas compactadas en aquél magno Congreso que representó la voluntad de muchos millares de personas de todo el Uruguay. En lo que a la Universidad refiere me permito recordar que en enero de 2004 publiqué en Brasil un artículo donde propuse abolir el Examen de Ingreso a la Universidad, implantar un sistema generalizado de becas en las Universidades públicas y crear el Servicio Social Solidario para los graduados universitarios “...consistente en prestación de servicios compatible con su formación universitaria en la localidad e institución para la cual el Ministerio más allegado a dicha actividad lo designe (de preferencia en la región de residencia del alumno o la más próxima a ella) por un período de dos años y recibiendo una beca (de unos 5 salarios mínimos mensuales, con dotación extra para las localidades más aisladas)"; así 
el ex-alumno estaría retribuyendo por lo menos parcial y directamente a las comunidades más necesitadas, parte de la donación recibida del conjunto de la sociedad al frecuentar una entidad universitaria financiada total o parcialmente con recursos públicos; aún considero válida la idea, incluso para Uruguay, donde no hay Examen de Ingreso a la Universidad pública.

Uruguay invertía en Educación hasta el 2004 sólo el 2,9\% de su PBI, mientras que la ONU recomienda un mínimo del $6 \%$; el gobierno del FA lucha a fines del 2007 para cumplir su promesa de elevar aquiél porcentaje hasta el $4,5 \%$, pero los sindicatos de profesores insisten que no lo está logrando, y varios conflictos (incluyendo huelgas) han sacudido el sector educativo uruguayo en los últimos meses. Como se ve, en el tema de la producción solidaria y ecológica, y en el tema de la educación (ambiental, como la queremos) el futuro de Uruguay sigue pendiente de la capacidad de lucha del pueblo y sus más aguerridos abanderados.

\section{Bibliografía del autor (libros en español)}

López Velasco, Sirio (1996, 1997, 2000). Ética de la Liberación: Vol. I Oiko-omia, CEFIL, Campo Grande, Brasil, Vol. II Erótica-Pedagogía-Individuología, d. CEFIL, Campo Grande, Brasil, Vol. III Política socioambiental ecomunitarista, Ed. Edgraf, Rio Grande, Brasil.

(2003) Ética para mis hijos y no iniciados, Ed. Anthropos, Barcelona, España.

(2007). Alias Roberto: diario ideológico de una generación, Ed. Baltgráfica, Montevideo, Uruguay. 